\title{
THE CELLULAR UPTAKE OF SENSITIZERS BOUND TO CYCLODEXTRIN CARRIERS
}

\author{
Hana Kolářová ${ }^{1}$, Martin Huff ${ }^{1}$, Jaroslav Maceček ${ }^{1}$, Pavla Nevřelová ${ }^{1}$, Marek Tomečka ${ }^{1}$, Robert Bajgar ${ }^{1}$, Jiří Mosinger ${ }^{2}$, \\ Miroslav Strnad ${ }^{1}$
}

Palacky University Olomouc, Faculty of Medicine, Czech Republic: Department of Biophysics, Laboratory of Growth Regulators ${ }^{1}$; Charles University in Prague, Faculty of Science, Czech Republic: Department of Inorganic Chemistry ${ }^{2}$

Summary: Photodynamic therapy of cancer uses the interaction of sensitizers and light to destroy cancer cells. In this study we tested the cellular uptake of meso-tetrakis(4-sulfonatophenyl)porphine (TPPS4) and its complex PdTPPS4 in the presence or absence of 2-hydroxypropyl-cyclodextrins (hpCDs) on G361 human melanoma cells. Self-fluorescence in G361 cells were measured by Perkin-Elmer LS50B luminometer equipped with well plate reader accessory. Morphological changes in cells have been evaluated using inversion fluorescent microscope Olympus IX 70 and image analysis. The uptake of the sensitizer PdTPPS4 at the given time interval from 1 to 48 hours is markedly higher than the uptake of TPPS4. The highest uptake was found for sensitizer PdTPPS4 in combination with hp $\beta C D$. TPPS4 and PdTPPS4 especially in the supramolecular complex with nontoxic cyclodextrin carriers represent efficient sensitizers for photodynamic therapy in vitro on G361 cells.

Key words: Sensitizers; Uptake; G361 human melanoma cells

\section{Introduction}

Photodynamic therapy (PDT) is a treatment for neoplastic disease that involves the selective destruction of tumors using light-activated sensitizer compounds that preferentially accumulate in target tissue areas $(1,4,8)$. The photochemical interactions of the sensitizer, light, and molecular oxygen produce cytotoxic singlet oxygen and other forms of active oxygen, such as peroxide, hydroxyl radical and superoxide ion resulting in damage of organelles within malignant cells and leads to tumor ablation $(2,9)$. The major sites of PDT damage are membranous organelles, such as mitochondria, lysosomes and plasma membrane. The efficiency of sensitizers in situ is most likely to be dependent on their local accumulation and specific cellular uptake in the tumor site, stimulating research toward the development of water soluble and efficient in vivo sensitizer - delivery system with a high potencial to target specific organs. In the present study we used meso-tetrakis(4-sulphonatophenyl)porphine (TPPS4) and paladium complex of TPPS4 (PdTPPS4) as model sensitizers $(6,7)$. We report here the uptake of a sensitizer into G361 human melanoma cells in the presence or absence of 2-hydroxypropyl- $\beta$-cyclodextrin $(\mathrm{hp} \beta \mathrm{CD})$.

\section{Material and methods}

Cellular uptake: The G361 cells (ATTC, USA) were divided in the amount of $10^{4}$ to each well (Dynatech plates 8 $\mathrm{x} 12$, flat bottom) and filled in DMEM with $10 \%$ FCS. The sensitizer was added into the holes in concentrations of $0 ; 0.1 ; 0.3 ; 1 ; 3 ; 10 ; 30$ and $100 \mathrm{mM}$ in the absence or presence of hpCDs in a 100-fold concentration excess compared to the sensitizer. The cells were incubated in a thermobox $\left(37^{\circ} \mathrm{C}, 5 \% \mathrm{CO}_{2}\right)$. After $1 ; 3 ; 6 ; 10 ; 16 ; 24$ and 48 hours of incubation, the medium above the adhering cells was removed. Each emptied hole was $2 \mathrm{x}$ washed with $120 \mu \mathrm{l}$ of DMEM. After washing $100 \mu \mathrm{l}$ of DMEM was added into each hole and self-fluorescence (TPPS4 excitation at $415 \mathrm{~nm}$, emission at $645 \mathrm{~nm}$, PdTPPS 4 excitation at $423 \mathrm{~nm}$, emission at $645 \mathrm{~nm}$ ) in G361 cells were measured with respect to individual sensitizer by Perkin-Elmer LS50B luminometer equipped with well plate reader accessory (Perkin-Elmer Corp., Norwalk, CT). The whole plate was read once with a read time of $0.2 \mathrm{~s}$ for each well. We found these settings optimal, increasing the read time per well and/or adjusting slit widths did not improve the signal to background ratio. Subsequently, from each of the holes $10 \mu \mathrm{l}$ of medium was withdrawn and the volume was replaced by 
the same one of $20 \%$ SDS. The holes were mildly shaken and incubated for 5 minutes; then their fluorescence was measured again.

Self-fluorescence of sensitizers in G361 cells: Twice washed trypsinated G361 cells were divided in the amount of $10^{4}$ to each well and filled in DMEM with $10 \%$ FCS in a total volume of $80 \mu \mathrm{l}$. After 24 hours of cultivation at $37^{\circ} \mathrm{C}$ in $5 \%$ $\mathrm{CO} 2$ the $20 \mu \mathrm{L}$ of sensitizer was added. Cells were cultivated with sensitizers at concentrations ranging from 0.1 to $125 \mu \mathrm{g} / \mathrm{ml}$. The total volume of $100 \mu \mathrm{l}$ (cells with additives) were cultivated for 24 hours. Cell uptake and morphological changes in cells have been evaluated using inversion fluorescent microscope Olympus IX 70 and image analysis.

\section{Results}

Fig. 1 shows that the uptake of the sensitizer PdTPPS4 at the given time interval is markedly higher than the uptake of TPPS4. The presence of the hpCD carrier did not affect the accumulation of TPPS4, but significantly affect uptake of PdTPPS4. The highest uptake was found for sensitizer PdTPPS4 in combination with $h p \beta C D$.

The presence of the hpCD significantly increases the level of an accumulation of PdTPPS4 in cells after a longtime period of incubation and gives no saturation character even after 48 hours of incubation. This is in contrary of free PdTPPS4 that reaches saturation after 24 hours (Fig. 2).

Self fluorescence of sensitizers in cells was evaluated by inversion fluorescent microscope Olympus IX 70 and image analysis. The major sites of cell uptake are plasma membrane, mitochondria and lysosomes (Fig. 3).

\section{Discussion}

Efficiency of PDT is affected by various factors including photophysical properties of a sensitizer, wavelength of the activation light, depth of the light penetration in the biological tissue, tissue response on singlet oxygen, etc. $(3,5,10)$. The wavelength of used light that activates the sensitizer dictates the proper absorption spectrum of a sensitizer as well as the depth of the treatment effect. Uptake of a sensitizer into tumor cells may vary depending on the metabolic state of individual cells. The measurement of the uptake of sensitizers into the G361cells shows the difference between the free sensitizers and bound to hpCD carriers. The kinetic of PdTPPS4 uptake is higher than for TPPS4. While the presence of $h p C D$ s does not notably affect the uptake of TPPS4, in the case of PdTPPS4 cyclodextrin carriers $h p \beta C D$ cause a significant magnification in accumulation of the sensitizer. The most effect on the level of distribution of the sensitizers in G361cells was found for PdTPPS4 in combination with hp $\beta C D$. G361 cells are sensitive to photodynamic damage by sensitizers in the presence or absence of hpCDs (3). In conclusion, PdTPPS4 and TPPS4 especially in the supramolecular complexes with hpCDs carriers represent efficient sensitizers.

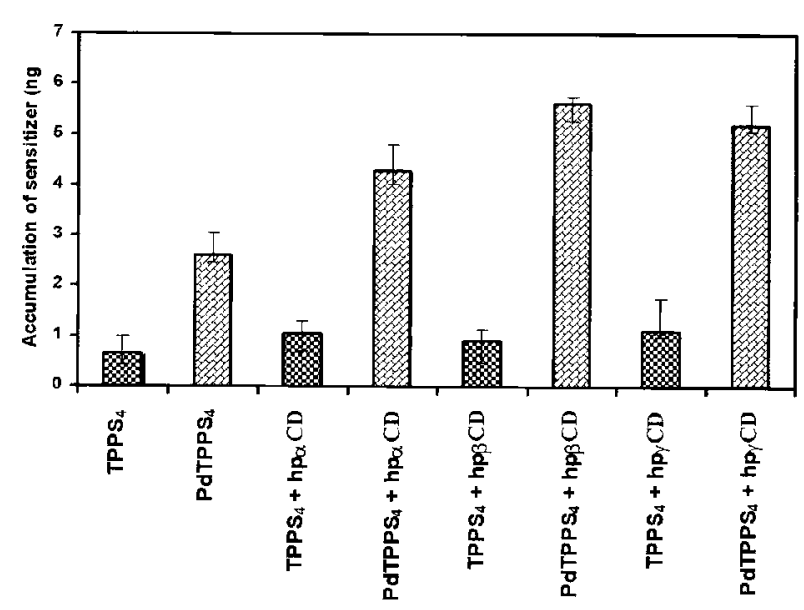

Fig. 1: The uptake of TPPS4 $(3 \mu \mathrm{M})$ and PdTPPS4 $(3 \mu \mathrm{M})$ sensitizers in the absence or presence of 100 fold molar excess of hpCDs into G361 cells $\left(10^{4}\right)$ after 24 hours of incubation in DMEM with 10\% FCS.

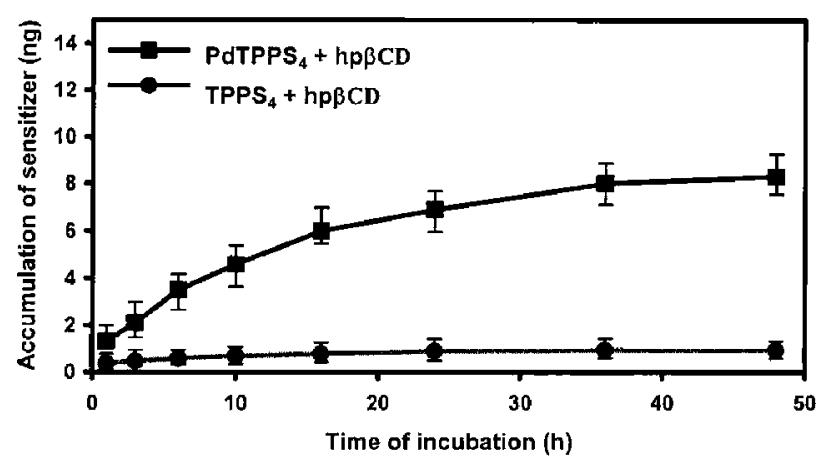

Fig. 2: Time dependent uptake of TPPS4 and PdTPPS4 sensitizers ( $3 \mu \mathrm{M}$ sensitizer, $10^{4} \mathrm{G} 361$ cells in DMEM with $10 \%$ FCS) bound to hp $\beta \mathrm{cd}$.

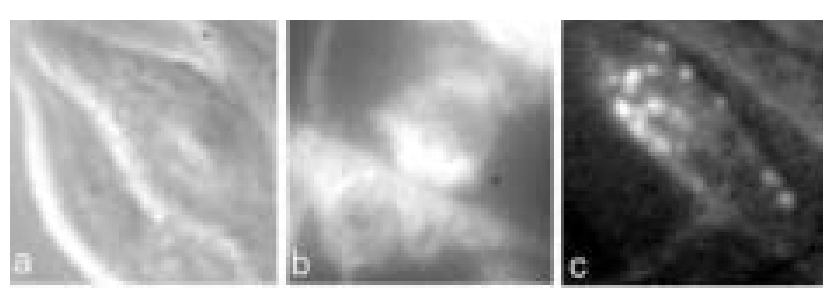

Fig. 3: Self fluorescence of PdTPPS4 sensitizer $(12 \mu \mathrm{g} / \mathrm{ml})$ bound to hp $\beta c d$ after 24 hours of cultivation in DMEM with 10\% FCS in G361cells. Excitation wavelength - 420 $\mathrm{nm}$. (3a: transmited light, 3b: accumulation of sensitizer on plasma membrane and mitochondria, $3 \mathrm{c}$ : accumulation of sensitizer on lysosomes.

\section{Acknowledgements}

The authors thank Olina Hustakova for assistance with tissue cultures. This work was supported by the grant project of Grant Agency No. 203/02/1483 and Ministry of Education MSM No. 153100008. 


\section{References}

1. Brown SB, Brown JE,Veron DI. Photosensitising drugs - their potential in oncology. Expert Opinion Invest Drugs 1999;8(12):1967-79.

2. Dahle J, Steen HB, Moan J. The mode of cells death induced by photodynamic treatment depends on cell density. J Photochem Photobiol B: Biology 1999; 70(3):363-7.

3. Koláŕová $H$, Mosinger J, Lenobel R, Kejlová K, Jírová D, Strnad M. In vitro toxicity testing of supramolecular sensitizers for photodynamic therapy. Toxicol in Vitro 2003;17(5-6):775-8.

4. Lui H, Anderson RR. Photodynamic therapy in dermatology: Recent developments. Dermatol Clin 1993;11:1-13.

5. Moor ACE. Signaling pathways in cell death and survival after photodynamic therapy. J Photochem Photobiol B: Biology 2000;57:1-13.

6. Mosinger J, Deumié M, Lang J, Kubát P, Wagnerová DM. Supramolecular sensitizer: complexation of meso tetrakis (4 sulfonatophenyl) porphyrin with 2-hydroxypropyl - cyclodextrins. J Photochem Photobiol A: Chemistry 2000;130:13-20.

7. Mosinger J, Mička Z. Quantum yields of singlet oxygen of metal complexes of meso tetrakis (4 sulfonatophenyl) porphyrin. J Photochem Photobiol A: Chemistry $1997 ; 107: 77-82$
8. Sibata Ch, Conlussi VC, Oleinick NL, Kinsella TJ. Photodynamic therapy in oncology. Expert Opinion Pharmacother 2001;2(6):917-27.

9. West CM. Size-dependent resistance of human tumour spheroids to photodynamic treatment. Br J Cancer 1989;59:510-4.

10. Zaidi SL, Oleinick NL, Zaim MT, Mukhthar H. Apoptosis during photodynamic therapy -induced ablation of RIF-1 tumors in $\mathrm{C} 3 \mathrm{H}$ mice: electron microscopic histopathologic and biochemical evidence. J Photochem Photobiol B: Biology 1994;58:771-6.

Doc. RNDr. Hana Kolářová, CSc., Palacky University Olomouc, Faculty of Medicine, Department of Biophysics, Laboratory of Growth Regulators, Hněvotínská 3, 77515 Olomouc, Czech Republic. e-mail kol@tunw.upol.cz 